REVISTA EVIDENCIAÇÃO CONTÁBIL \& FINANÇAS

João Pessoa, v.5, n. 1, p. 56-74, jan./abr. 2017. ISSN 2318-1001

DOI:10.18405/recfin20170104

Disponível em: http://periodicos.ufpb.br/ojs2/index.php/recfin

\title{
AUDIT COMMITTEE: UM ESTUDO DAS CARACTERÍSTICAS DAS EMPRESAS LISTADAS NA BM\&FBOVESPA ${ }^{1}$
}

\author{
AUDIT COMMITTEE: A STUDY OF THE CHARACTERISTICS \\ OF COMPANIES LISTED IN BMEFBOVESPA
}

\author{
Milena Araújo Rego Amorim² \\ Graduanda em Ciências Contábeis pela UFES \\ Bacharela em Ciências Econômicas pela UFES \\ Aluna da Universidade Federal do Espírito Santo (UFES) \\ milenaeco@hotmail.com \\ Carla Lira Miranda \\ Graduanda em Ciências Contábeis \\ Aluna da Universidade Federal do Espírito Santo (UFES) \\ carlalm2008@hotmail.com \\ Donizete Reina \\ Mestre em Ciências Contábeis pela UFSC \\ Professor da Universidade Federal do Espírito Santo (UFES) \\ dreina2@hotmail.com \\ Diane Rossi Maximiano Reina \\ Mestre em Ciências Contábeis pela UFSC \\ Professora da Universidade Federal do Espírito Santo (UFES) \\ dianereina@hotmail.com \\ Mirian Albert Pires \\ Mestre em Ciências Contábeis pela FUCAPE \\ Professora da Universidade Federal do Espírito Santo (UFES) \\ mirianalbert@yahoo.com.br
}

\section{RESUMO}

Objetivo: O objetivo deste estudo foi comparar as características dos comitês de auditoria de 65 empresas listadas na BM\&FBovespa nos anos de 2014 e 2015, com as obtidas anteriormente nos anos de 2012 e 2013.

Fundamento: O comitê de auditoria pode ser considerado um instrumento da governança corporativa, sendo formado por membros do conselho de administração, e sua composição deverá ser representada por membros independentes e especialistas na área da contabilidade ou financeira.

\footnotetext{
${ }^{1}$ Artigo recebido em: 27/09/2016. Revisado por pares em: 17/10/2016. Versão final recebida em: 08/11/2016. Recomendado para publicação em: 09/11/2016 por Wenner Glaucio Lopes Lucena (Editor Adjunto). Publicado em: 01/01/2017. Organização responsável pelo periódico: UFPB.

${ }^{2}$ Endereço: Rua Margarida do Amaral Pereira, 75, Tabuazeiro, Vitória/ES, CEP: 29.043-646.

DOI: http://dx.doi.org/10.18405/recfin20160104
} 
Método: Foram investigadas a expertise, a independência e o tamanho, sendo realizado um estudo descritivo, com abordagem quantitativa e pesquisa documental.

Resultados: Foi possível identificar que, em 2014, as áreas mais significativas foram engenharia, economia, administração e contabilidade, havendo poucas variações no ano de 2015. Quanto à independência dos membros, a maioria das empresas cumpriu com as boas práticas de governança corporativa, sendo que em 2014 aproximadamente 14\% das empresas não atenderam a este requisito. Com mediana de 3,0 membros e médias de 3,22 em 2014 e 3,20 membros em 2015, cumpriramse, em sua maioria, as recomendações da Comissão de Valores Mobiliários contidas na instrução ${ }^{\circ}$ 509, na Lei Sarbanes-Oxley e na Resolução BACEN no 3.198/04. No que se refere ao tamanho, os resultados mostram que 49 empresas, nos anos referenciados, continham três ou mais membros em seus comitês, correspondendo, respectivamente, a 75,3\% e 74,3\%.

Contribuições: Verificou-se que os comitês de auditoria não se apresentam de forma homogênea nas empresas e, mesmo com as recomendações de órgãos internos e da Lei Sarbanes-Oxley, apresentam-se de formas diversas.

Palavras-chave: Comitê de Auditoria; Governança Corporativa; Companhias Abertas.

\section{ABSTRACT}

Objective: This study proposed to determine the audit committee characteristics of 65 companies in the years 2014 and 2015, comparing them evaluations made in 2012 and 2013.

Background: The audit committee, formed by members of the board of directors, can be considered an instrument of corporate governance. Its composition should be represented by independent members and experts in the areas accounting or finance.

Method: The expertise was the feature investigated. A descriptive study was conducted with a quantitative approach and documentary research.

Results: It was identified that in 2014, considered the total of 209 members, the most significant areas were engineering, economics, management and accounting, with few variations in 2015. As for the independence of the members, most companies comply with good corporate governance practices. The median was 3 members, while the averages were 3,22 members in 2014 and 3,20 in 2015. Most audit committees do not have a homogeneous composition, despite the Securities and Exchange Commission recommendations (Instruction No. 509), the Sarbanes-Oxley Law and BACEN Resolution (No. 3198/04). Regarding size, the results show that 49 companies in the referenced years had three or more members in their committees, corresponding respectively to $75.3 \%$ and $74.3 \%$.

Contributions: It was also verified that the audit committees do not present themselves evenly in the companies and, even with the recommendations of internal organs and those of the SarbanesOxley Act, they present themselves in different ways.

Keywords: Audit Committee; Corporate Governance; Public Companies.

\section{INTRODUÇÃO}

Segundo o Instituto Brasileiro de Governança Corporativa (IBGC, 2009), a governança corporativa é o sistema pelo qual as organizações são dirigidas, monitoradas e incentivadas, envolvendo relacionamentos entre proprietários, conselho de administração, diretoria e órgãos de controle, com a finalidade de preservar e aperfeiçoar o valor da organização, melhorando o seu acesso a recursos e contribuindo para sua longevidade. São princípios básicos de governança corporativa: a transparência, que resulta em um clima de confiança, tanto internamente quanto nas relações da empresa com terceiros; a equidade a todos os sócios e demais partes interessadas (stakeholders); a prestação de contas (accountability) de suas atuações, assumindo integralmente as consequências de seus atos e omissões, e a responsabilidade corporativa. 
Para a BM\&FBovespa, a governança corporativa é o conjunto de mecanismos de incentivo e controle que visam assegurar que decisões sejam tomadas em linha com os objetivos de longo prazo das organizações, visando principalmente alcançar as metas estratégicas e a criação de valor para todos os seus acionistas, respeitando os relacionamentos com as partes interessadas (stakeholders).O IBCG (2009), com o intuito de alcançar as melhores práticas de governança corporativa, ressalta a importância da criação de comitês especializados. Incentivando estes conselhos a formarem o comitê de auditoria, preferencialmente compostos por membros do conselho de administração, para analisar as demonstrações financeiras, promover a supervisão e a responsabilização da área financeira; garantir que a diretoria desenvolva controles internos confiáveis, monitorando adequadamente que a auditoria interna desempenhe a contento o seu papel, e que os auditores independentes avaliem, por meio de sua própria revisão, as práticas da diretoria e da auditoria interna. O comitê deve verificar o cumprimento do código de conduta da organização, quando não houver outro órgão para essa finalidade.

O comitê de auditoria deverá ter pelo menos um integrante com experiência comprovada na área contábil ou de auditoria. Este comitê busca que as atividades nas empresas sejam mais transparentes. Segundo Furuta (2010), alguns pesquisadores, órgãos reguladores e governamentais questionam a efetividade do trabalho do comitê de auditoria. Essa desconfiança é notada devido aos escândalos ocorridos, desde o ano 2000, no mercado de capitais norte-americano, que envolveram empresas como a Enron (setor de energia, em 2001), WorldCom (telecomunicações, em 2002) e Arthur Andersen (empresa de auditoria, em 2002), entre outras, com casos de fraudes contábeis e falhas nos controles internos. Isto originou a preocupação em relação ao efetivo monitoramento realizado pelo comitê de auditoria, já que é responsável pela qualidade das demonstrações contábeis.

A Lei Sarbanes-Oxley foi criada nos EUA, em 2002, com o propósito de evitar maiores prejuízos e visa a recuperação da credibilidade do mercado, evitando o surgimento de novas fraudes nas empresas. Essa lei possui uma das mais rigorosas regulamentações sobre o estabelecimento de controles internos, além da elaboração de relatórios financeiros e a divulgação de informações. Adotada por companhias abertas norte-americanas, por todas as empresas estrangeiras com ações negociadas no mercado norte-americano, e por subsidiárias de multinacionais registradas nas bolsas norte-americanas, mas operando em outros países, a Lei Sarbanes-Oxley criou um novo ambiente de governança corporativa e proporcionou um conjunto de novas responsabilidades e sanções aos administradores, coibindo práticas lesivas e que exponham as sociedades anônimas a elevados níveis de riscos, sendo uma de suas principais características a responsabilidade penal da diretoria das empresas.

Segundo Cunha et al. (2013), em relação ao comitê de auditoria, a Lei Sarbanes-Oxley, na seção 205, aborda que o comitê de auditoria é um órgão estabelecido pelo conselho de administração para efeitos de supervisão da contabilidade e de relatórios financeiros. Furuta et al. (2010), aborda que na seção 301 o comitê de auditoria é o responsável direto pela contratação, compensação e supervisão da empresa, que de modo independente deverá preparar os relatórios de auditoria e trabalhos relacionados, e atuar na resolução de quaisquer conflitos que possam existir sobre relatórios contábeis entre a administração e auditores independentes. Ou seja, o comitê de auditoria possui a responsabilidade, em nome do conselho de administração, de garantir a integridade dos relatórios financeiros, logrado por meio da supervisão dos controles internos e do processo de preparação e divulgação desses relatórios.

Pode-se dizer que o comitê de auditoria é uma importante fonte de governança corporativa dentro da estrutura de controle da empresa. Destaca-se que este trabalho se baseou no artigo de Cunha et al. (2013), que analisou as características do comitê de auditoria, tais como tamanho, que se refere à quantidade de membros que compõem o comitê; a independência, que é representada 
pela quantidade de membros que não possuem vínculo ou subordinação a outros níveis na mesma organização, e a expertise, que verifica a formação ou experiência profissional.

O estudo concluiu que a criação do comitê de auditoria ainda não é uma prática institucionalizada pelas empresas brasileiras, e que este se manifesta de formas distintas entre as organizações. Como o estudo de Cunha et al. (2013) trata do tema no período de 2010 a 2013, a proposta desta pesquisa é observar o assunto entre os anos de 2014 e 2015.O Blue Ribbon Committee (1999), com relação à característica de tamanho, indica que o comitê de auditoria deve ser composto por três membros, no mínimo. O IBGC não especifica um número que seja adequado para a formação do comitê de auditoria; já a Comissão de Valores Mobiliários, em sua instrução n 509 , determina que o comitê de auditoria seja composto por no mínimo três membros, indicados pelo conselho de administração, tendo ao menos, 1 (um) membro do conselho, que não participe da diretoria; e que a maioria dos membros seja independente.

A Lei Sarbanes-Oxley determina que o comitê de auditoria deverá ser composto por no mínimo três membros do conselho de administração, e que um de seus membros seja um especialista financeiro, com conhecimentos de demonstrações e princípios contábeis.Para o IBGC (2009), a independência é uma característica do comitê de auditoria que analisa a capacidade de exercer julgamentos, recomendando que seja constituído, preferencialmente, por conselheiros independentes ou, pelo menos, que sua maioria seja independente. Os estudos de Klein (2002) apontam que quanto maior a quantidade de membros independentes que fazem parte do comitê de auditoria, melhor é a qualidade das informações contábeis.

A característica expertise refere-se ao conhecimento e experiência que o membro do comitê de auditoria possui em contabilidade, auditoria e/ou finanças. Para o IBGC (2009), o comitê de auditoria deverá ter pelo menos um integrante com experiência comprovada na área de contabilidade, auditoria e/ou finanças. A recomendação do Blue Ribbon Committee (1999) é de que no mínimo três membros tenham conhecimento na área financeira, ou que busquem este conhecimento após o período da sua nomeação, e que pelo menos um destes membros tenha conhecimentos aprofundados sobre os princípios contábeis, demonstrações financeiras e procedimentos usuais de auditoria. Para Chatterjee (2011), o comitê de auditoria deverá ter, no mínimo, três membros independentes, e que no mínimo um possua conhecimentos em contabilidade e finanças.

Dada a importância do comitê de auditoria como elemento fundamental de governança corporativa, e tendo como referência às recomendações do IBCG, da Comissão de Valores Mobiliários, em sua instrução n 509, da Lei Sarbanes-Oxley e da Resolução BACEN nº 3.198/04, surge o seguinte problema de pesquisa: as empresas listadas na Bovespa, que possuem comitê de auditoria, apresentam quais características?A questão central da pesquisa é apresentar quais são as os perfis que predominam no comitê de auditoria das empresas listadas na BM\&FBovespa, com foco nos atributos de tamanho, independência e expertise, e comparar as mudanças observadas entre artigos. Assim, o objetivo deste estudo é verificar as características do comitê de auditoria de 65 empresas nos anos de 2014 e 2015, comparativamente aos anos de 2012 e 2013.

O estudo está estruturado em cinco seções, iniciado com essa introdução; seguido pela fundamentação teórica que aborda o comitê de auditoria, governança corporativa e a Lei SarbanesOxley; os estudos assemelhados, que abordarão o estado da arte, mostrando trabalhos realizados sobre o tema em estudo; os resultados obtidos e, ao fim, as conclusões.A contribuição deste estudo é apresentar a importância do comitê de auditoria, já que empresas brasileiras que possuam ações negociadas no mercado norte-americano devem atender às regras da lei Sarbanes-Oxley, sendo uma delas a criação do comitê de auditoria, buscando sempre as melhores práticas de governança corporativa e transparência, abordando o que os órgãos reguladores sugerem sobre características do comitê das empresas brasileiras, e comprando-as com estudos anteriores. 


\section{REFERENCIAL TEÓRICO}

\subsection{Committee Audit e Governança Corporativa}

O comitê de auditoria é um órgão da governança corporativa, que é formado por membros do conselho de administração, e a sua formação deverá ser composta por membros independentes e especialistas na área da contabilidade ou financeira. Conforme a seção 205 (conforming amendments) da Lei Sarbanes-Oxley, o comitê de auditoria significa: (a) um comitê, ou órgão equivalente, criado pelo e para o conselho de administração de um emissor, para efeitos de supervisão dos processos de contabilidade e de informação financeira, e das auditorias das demonstrações financeiras.

De acordo com a Seção 301 da Sarbanes-Oxley, cabe ao comitê de auditoria a criação de procedimentos para receber, processar e tratar as denúncias, anônimas ou não, relativas à contabilidade da empresa e análise da adequada aplicação dos princípios contábeis, de controles internos contábeis e de questões relacionados à auditoria. Cabe ainda garantir a confidencialidade e o anonimato dos empregados, relativamente às reclamações questionáveis de contabilidade e auditoria. O comitê de auditoria poderá realizar a contratação de consultores independentes, caso seja necessário.

De acordo com Santos (2009), o comitê de auditoria destacou-se devido aos escândalos financeiros ocorridos nos anos 2000 e a situação vivenciada por grandes empresas, como a Enron, WorldCom, entre outras. Os investidores ficaram desconfiados com a real situação do mercado de capitais, isso fez que vários países criassem ou aperfeiçoassem os órgãos reguladores, o Brasil foi um deles que, aplicaram medidas legais e emitiram diversas normas. Destacam-se os elementos de controles, que ocasionaram o surgimento da governança corporativa, presente por conselhos e comitês, com o objetivo de garantir que os relatórios emitidos pelas empresas demonstrassem com a maior transparência e fidedignidade da situação econômica e financeira.

Almeida (2008) aborda que o tema governança corporativa tomou corpo no Brasil nos anos de 1990 com a onda de privatizações implementadas pelo governo de Fernando Henrique Cardoso e da expansão dos fundos de pensão como investidores institucionais, tendo como objetivo transpor o obstáculo da alta concentração de poder nas mãos de acionistas controladores. Nos Estados Unidos, o surgimento da boa governança corporativa foi uma forma de reverter os efeitos negativos do exagerado poder dos executivos e, também, do frágil papel dos acionistas sobre o desempenho das companhias.

Segundo Iudícibus e Lopes (2004), a governança corporativa surgiu da necessidade de regulação entre agentes econômicos, a fim de minimizar os conflitos de agência existentes entre si. Peleias et al. (2009) definem a governança corporativa como o conjunto de práticas que buscam o desenvolvimento econômico-financeiro da empresa por meio de mecanismos que harmonizem as relações entre as partes (acionistas e gestores). Para Silveira (2010, p. 2), a governança corporativa é "o conjunto de mecanismos que visam a fazer com que decisões corporativas sejam sempre tomadas com a finalidade de maximizar a perspectiva de geração de valor de longo prazo para o negócio".

A Comissão de Valores Mobiliários (CVM, 2002) estabelece a definição de governança corporativa como sendo um conjunto de práticas com vistas a protege os interessados como investidores, empregados, credores etc. O IBCG (2009) define a governança corporativa como sendo o sistema pelo qual as empresas e demais organizações são dirigidas, monitoradas e incentivadas, envolvendo os relacionamentos entre sócios, conselho de administração, diretoria, órgãos de fiscalização e controle e demais partes interessadas. Ainda, segundo o IBCG (2009), apresenta como princípios básicos da governança corporativa a transparência, disponibilizando as partes interessadas informações de seu interesse, buscando a transparência das informações e a confiança tanto 
internada empresa, quanto com terceiros. A equidade, através do tratamento justo e isonômico de todos os sócios e demais partes interessadas (stakeholders).

Segundo Furuta (2010), alguns pesquisadores, órgãos reguladores e governamentais questionam a efetividade do trabalho do Comitê de Auditoria. Essa desconfiança é notada devido aos escândalos ocorridos, desde o ano 2000, no mercado de capitais norte-americano, que envolveram empresas como a Enron (setor de energia, em 2001), WorldCom (telecomunicações, em 2002) e Arthur Andersen (empresa de auditoria, em 2002) entre outras, com casos de fraudes contábeis e falhas nos controles internos. Isto originou a preocupação em relação ao efetivo monitoramento realizado pelo comitê de auditoria, já que é responsável pela qualidade das demonstrações contábeis.

De acordo com Almeida (2008), os problemas de governança corporativa que foram constatados com os escândalos no início de 2000 fizeram com que os legisladores americanos exigissem do comitê de auditoria novas responsabilidades e formas de atuação, para serem mais eficazes nos processos operacionais. Porém, para Furuta (2010), se há a expectativa de que o comitê de auditoria possibilite uma maior transparência nas atividades sociais da empresa, por outro lado, os órgãos reguladores, governamentais e pesquisadores de vários países questionam sobre a existênciado comitê de auditoria e sua contribuição para a governança corporativa. Segundo Felo et al. (2003), o comitê de auditoria da Enron foi instalado de forma opcional quando não era uma exigência imposta pela Sarbanes-Oxley, sendo formado por membros altamente qualificados, mas que não foram capazes de identificar as irregularidades praticadas pela empresa.

Nesse contexto, a atuação do comitê de auditoria foi considerada um dos pilares da reconstrução da credibilidade dos investidores nas demonstrações contábeis e demais informações sobre desempenho operacional, fornecidas pelas companhias de capital aberto.

O comitê de auditoria faz parte das exigências da Sarbanes-Oxley. No Brasil, o comitê de auditoria não é obrigatório. De acordo com Antunes et al. (2007), tem-se a figura legal do conselho fiscal que exerce a função de órgão de fiscalização dos administradores e de informação aos acionistas. Com isso, a SEC conferiu a possibilidade de o conselho fiscal das empresas brasileiras exercerem as funções de comitê de auditoria requerido pela lei Sarbanes-Oxley e, portanto, substituílos, à opção da sociedade. Segundo o IBCG (2009, p. 16), “a legislação norte-americana admite o conselho fiscal para exercer tal papel as empresas brasileiras".

De acordo com Silva et al. (2009, p. 48), as companhias brasileiras têm duas opções: "adotar um comitê de auditoria nos exatos termos contidos nas normas da SEC; ou constituir e/ou utilizar comitês equivalentes para o exercício das funções do comitê de auditoria (no caso do Brasil, o conselho fiscal)". A Resolução n. 3.170/04 distinguiu o conselho fiscal do comitê de auditoria, além de proibir a participação no comitê de auditoria de quem seja ou tenha sido membro do conselho fiscal nos últimos 12 meses.

Segundo Almeida (2008, p.47), “a exigência em constituir o Comitê de Auditoria para as empresas brasileiras está limitada às instituições financeiras de grande porte". Baioco (2015), além de separar claramente o comitê de auditoria do conselho fiscal, não permite sua substituição. $\mathrm{O}$ mesmo para Resolução n. 118/04 do Conselho Nacional de Conselho Nacional de Seguros Privados (CNSP) (2004), dado que também faz essa exigência para as seguradoras que possuem o Patrimônio Líquido igual ou superior a quinhentos milhões ou provisões técnicas em valor igual ou superior a setecentos milhões, as sociedades de capitalização e as entidades de previdência complementar.

Na percepção de Silva et al. (2009, p. 47), segundo “as regras norte-americanas, o comitê de auditoria deverá fazer parte do conselho de administração, e sua composição será de pelo menos três membros independentes - não só da gestão e da auditoria externa, como também dos controladores". De acordo com Almeida (2008, p. 22) o principal objetivo de um comitê de auditoria é "o 
de auxiliar o conselho de administração na supervisão da integridade das demonstrações financeiras; da adequação da empresa com as exigências de leis e regulamentos; da independência e das qualificações do auditor independente e do desempenho dos auditores independentes e da função de auditoria interna da empresa". Para Oliveira e Linhares (2007), a função do comitê de auditoria é atuar junto ao conselho de administração e ficar atento ao cumprimento do regulamento interno das empresas; efetuar uma análise detalhada das demonstrações contábeis; garantir a existência de processo sólido para o monitoramento de riscos; controlar a elaboração e apresentação dos relatórios financeiros; avaliar os processos de auditoria e criticar as ineficiências de controle interno, buscando a diminuição de fraudes.

Silva $(2007$, p. 62) apresenta as seguintes penalidades previstas pelo descumprimento da SOX: "pela certificação de qualquer demonstrativo em desacordo com as exigências estipuladas: U\$ 1.000 .000 ou a reclusão por 10 anos, ou ambos e pela certificação, intencional, de qualquer demonstrativo em desacordo com as exigências estipuladas: U\$ 5.000 .000 ou a reclusão por 20 anos, ou ambos".

A Resolução 3.198/04, no seu Art. 12 e a Resolução № 3.170/04, em seu Art. 11 do Banco Central do Brasil (BACEN), abordam que o comitê de auditoria deve ser composto, no mínimo, por três integrantes, observado que o mandato máximo deve ser de cinco anos para as instituições com ações negociadas em bolsa de valores e sem mandato fixo para aquelas de capital fechado. Pelo menos um dos integrantes do comitê de auditoria deve possuir comprovados conhecimentos nas áreas de contabilidade e auditoria que o qualifiquem para a função. Para a CVM (2002) o comitê de auditoria deverá ser composto por membros do conselho de administração com experiência em finanças, incluindo pelo menos um conselheiro que represente os minoritários, que deve supervisionar o relacionamento com o auditor.

Para o IBCG (2015, p. 79), o “comitê de auditoria, preferivelmente, deverá ser formado apenas (ou ao menos em sua maioria) por conselheiros independentes e coordenados por um conselheiro independente. Dada a grande possibilidade de conflitos de interesses, não convém possuir conselheiros internos ou executivos em sua composição, devendo estes últimos ser convidados para as reuniões, quando necessário". Quanto à expertise, ao menos um de seus membros deve ter experiência comprovada na área contábil, financeira ou de auditoria. Em relação à quantidade de membros (IBCG, 2015, p. 59), “o comitê deve ser composto de, no mínimo, três membros, todos com conhecimentos sobre o tópico em questão, e deve contar com, ao menos, um especialista em seus respectivos temas".

\subsection{Estudos Assemelhados}

Chiodini et al. (2013) analisaram se o comitê de auditoria das maiores empresas de capital aberto no Brasil está adequado às recomendações emanadas pelo IBGC e pela Cartilha da CVM. Os resultados apresentaram que grande parte das companhias, por exigência ou não, constituíram um comitê de auditoria ou o conselho fiscal adaptado, buscando-se atender às boas práticas de governança corporativa.

Em seu estudo Erkens e Bonner (2013) examinaram 1500 empresas, durante os anos 1999 até 2008, para verificar as nomeações de especialistas financeiros no comitê de auditoria, e se a presença destes profissionais está associada a relatórios financeiros com menores reformulações. A conclusão foi que as empresas preferem a nomeação de indivíduos com status mais elevados, e nem sempre estes indivíduos são considerados especialistas financeiros, elevando assim, a probabilidade de correções dos relatórios financeiros.

Cunha et al. (2013) verificaram se as características atreladas ao comitê de auditoria refletem no gerenciamento de resultados nas empresas listadas na BM\&FBovespa, em diferentes segmentos. Os resultados apontaram que não é possível considerar que existe relação entre as variáveis do 
comitê de auditoria com o gerenciamento de resultados. Cunha et al. (2014) observaram se características do comitê de auditoria refletem no gerenciamento de resultados das empresas brasileiras listadas na BM\&FBovespa. Os resultados mostraram que a maioria dos comitês de auditoria é composta por até três membros, sendo até dois membros considerados independentes. Sobre a expertise, nota-se uma distribuição igual de frequência para empresas com um e dois membros, formados na área contábil ou em áreas afins da área financeira. $\mathrm{O}$ estudo concluiu que nenhuma das características do comitê de auditoria estudada apresentou influência sobre o gerenciamento de resultados.

Furuta e Santos (2010) foram obter a opinião dos executivos das empresas que operam no Brasil e que negociam seus títulos no mercado norte-americano e dos analistas de mercado sobre a formação do comitê de auditoria ou do conselho fiscal adaptado. Os resultados mostraram que a maioria das empresas que formaram o comitê de auditoria considera o nível de governança corporativa na decisão de formar o comitê ou adaptar o conselho fiscal às funções do comitê de auditoria. Grande parte dos executivos das empresas e os analistas de mercado concordaram que o comitê de auditoria pode ser visto como um mecanismo de monitoramento da gestão da companhia.

Cunha et al. (2015) analisaram a relação entre as características do comitê de auditoria e o audit delay, no período de 2012. Foram analisadas as seguintes características do comitê de auditoria: tamanho, independência e expertise. Os resultados obtidos informam uma relação inversa entre as características do comitê de auditoria com o audit delay, ou seja, quanto maior o comitê de auditoria e maior o número de membros independentes e que tenham conhecimentos em finanças, contabilidade e auditoria, menor será o prazo de entrega do parecer de auditoria independente. Já Guariente (2008), investigou a importância do comitê de auditoria na implementação das boas práticas de governança corporativa nas instituições financeiras brasileiras com ações ou títulos negociados no mercado de capitais norte-americano, e concluiu que os comitês de auditoria analisados são efetivos e contribuem para o estabelecimento de um processo de controles interno robusto que favorece a adoção das boas práticas de governança corporativa.

Guzzo (2014) buscou identificar as características e interligações com outros tipos de comitês e conselhos de empresas listadas na BM\&FBovespa do segmento Novo Mercado. As características abordadas foram: a faixa etária em idade, gênero, expertise, tamanho, profissões e os históricos profissionais. Em média, o tamanho do comitê é de três integrantes, e apenas $6 \%$ correspondem ao gênero feminino. A faixa etária mais frequente é acima de 56 anos. Quanto à formação profissional dos integrantes, as mais comuns são Engenharia, Economia, Finanças e Contabilidade. A conclusão, quanto a característica da expertise e as sugestões de governança corporativa emanadas pelo IBGC e CVM, foram satisfatórios, já que mais da metade de seus membros possui conhecimento financeiro.

O estudo de Baioco (2015) investigou os efeitos da instalação e das características do conselho fiscal e do comitê de auditoria sobre a qualidade das informações contábeis no Brasil de empresas listadas na BM\&FBovespa, durante os anos de 2010 a 2013. A instalação do conselho fiscal causou um impacto positivo à relevância do patrimônio líquido, enquanto a instalação do comitê de auditoria à relevância do lucro. Esses resultados podem indicar que há diferenças no direcionamento da atenção desses órgãos: em proteger o patrimônio da entidade para os acionistas (conselho fiscal) ou em assegurar números mais confiáveis sobre o desempenho dos administradores (comitê de auditoria).

Santos (2009) identificaram e analisaram os aspectos mais relevantes que caracterizam o comitê de auditoria. Os resultados mostraram que a maioria das 112 empresas pesquisadas não apresentaram um grau de evidenciação sobre o comitê de auditoria que permitia uma visualização mais efetiva sobre esse organismo nas organizações. 
Almeida (2008) realizou um levantamento bibliográfico com o objetivo de apresentar as diferenças entre o mercado de capitais no Brasil e nos Estados Unidos da América, além de identificar as atribuições impostas aos Comitês de Auditoria, bem como a aderência dessas atribuições aos Regimentos Internos desses dois órgãos. O estudo verificou não só o grau de atendimento em relação a essas atribuições, mas também o nível de similaridade de funções estabelecidas pelos Comitês de Auditoria e Conselhos Fiscais pesquisados e os resultados da pesquisa comprovaram que não há homogeneidade nas atribuições destes dois órgãos.

O estudo de Chiachio et al. (2015) analisou 78 empresas listadas na BM\&FBovespa e constatou que, em relação ao tamanho do comitê, a maioria das empresas atende às recomendações do IBGC quanto a possuir no mínimo 3 membros; em relação à independência dos membros, a maioria das empresas da amostra não atende às recomendações do IBGC; e quanto a expertise, as empresas estão de acordo com o mínimo determinado pelo IBGC que recomenda o mínimo de 1 membro, e grande parte das empresas não divulgam as informações sobre a quantidade de reuniões do comitê. Apenas três empresas atingiram o índice de nível de aderência alto, sendo pertencente ao segmento Novo Mercado. A análise de regressão constatou que há evidências que o nível de governança corporativa das empresas pertencentes à BM\&FBovespa tem influência positiva no índice do nível de aderência daquelas do IBGC.

Peleias et al. (2009) investigou a percepção dos gestores de empresas brasileiras emitentes de ADR's, obrigadas a atender à SOX, se o comitê de auditoria ou órgão equivalente contribui para minimizar as fraudes, aumentar a transparência na divulgação das informações contábeis e reduzir falhas nos controles internos. A pesquisa analisou 34 empresas brasileiras, à época emitentes de ADR's, e os resultados obtidos demonstraram que o comitê de auditoria foi adotado por $47 \%$ das empresas pesquisadas, e que $71 \%$ o manteriam em funcionamento, mesmo que no futuro a SOX facultasse sua obrigatoriedade. Segreti et al. (2007) realizaram uma pesquisa exploratória sobre a implantação do comitê de auditoria em empresas brasileiras conforme a Lei Sarbanes-Oxley e buscaram investigar a percepção dos gestores de empresas emitentes de ADR's, obtendo resultados parecidos.

\section{METODOLOGIA DA PESQUISA}

Foi realizado um estudo de natureza descritiva, com abordagem quantitativa e pesquisa documental, com o objetivo de verificar as características do Comitê de Auditoria das empresas listadas no site da BM\&FBovespa (www.bmfbovespa.com.br) que atuaram no Brasil entre os anos de 2014 e 2015.

O estudo é descritivo, pois trabalhos como esse "medem, avaliam e coletam dados sobre diversos aspectos, dimensões ou componentes do fenômeno a ser pesquisado" (Sampieri, Collado, \& Lucio, 2006, p. 101), e quantitativo, pois segundo Marconi e Lakatos (2011, p. 269) “[...] adota amostras amplas e de informações numéricas, enquanto que no método qualitativo as amostras são reduzidas, os dados são analisados em seu conteúdo psicossocial e os instrumentos de coleta não são estruturados". A pesquisa também é documental, pois utilizou-se de informações disponibilizadas no site da BM\&FBovespa (Lakatos, \& Marconi, 2011).

A amostra concentrou-se nas empresas listadas no site da BM\&FBovespa. De um total de 495 empresas pesquisadas, 65 empresas possuíam comitê de auditoria em 2014 e 66 em 2015. Foram excluídas as empresas sem comitê de auditoria e as instituições financeiras e seguradoras, pois são vinculadas aos órgãos reguladores BACEN e SUSEP, respectivamente. Estes órgãos possuem regulamentações próprias.

As informações referentes às características do comitê de auditoria foram coletadas através do Formulário de Referência, subseção 12.7, nas informações referentes à composição de todos os comitês ligados ao conselho de administração. Neste formulário foram observadas as informações 
referentes ao tamanho, expertise e independência do comitê de auditoria das empresas pesquisadas. Para análise dos dados, utilizou dos instrumentos de estatística descritiva como: mínimos e máximos, médias, moda, desvio padrão etc.

\section{DESCRIÇÃO E ANÁLISE DOS RESULTADOS}

O presente estudo verificou que em relação à Governança Corporativa, a maioria das empresas concentra-se no segmento Novo Mercado. De acordo com a BM\&FBovespa, todos os segmentos prezam por rígidas regras de governança corporativa e têm como objetivo melhorar a avaliação daquelas que decidem aderir, voluntariamente, a um desses segmentos de listagem.O Novo Mercado foi criado em 2000 como segmento diferenciado de listagem destinado à negociação de ações emitidas por companhias que se comprometem com a adoção de práticas de governança corporativa adicionais às exigidas pela legislação em vigor brasileira e que incluem a implementação de um conjunto de regras societárias que ampliam os direitos dos acionistas e de uma política de divulgação de informações mais transparente e abrangente. Em 2014, 64,62\% das empresas pesquisadas encontram-se no Novo Mercado, enquanto que em 2015 este valor caiu para 62,12\%. Mesmo com redução, continua sendo o segmento com mais empresas listadas.

Houve um aumento das empresas sem segmento, em 2014 com 13,85\% e em 2015, com 15,15\% os segmentos Nível 2, Nível 1G.V, Nível 2G.V e Companhia Balcão tiveram o mesmo número de empresas nos anos de 2014 e 2015, o percentual teve uma pequena alteração devido a diferença no total de empresas pesquisas em cada ano, conforme Tabela 1.

\begin{tabular}{l|c|c|c|c}
\multicolumn{5}{c}{ Tabela1 - Níveis de Governança Corporativa } \\
\hline Nível de Governança & $\mathbf{2 0 1 4}$ & $\mathbf{\%}$ & $\mathbf{2 0 1 5}$ & $\mathbf{\%}$ \\
\hline Nível 1 & 2 & 3,08 & 3 & 4,55 \\
Nível 2 & 2 & 3,08 & 2 & 3,03 \\
Nível 1 G. V & 5 & 7,69 & 5 & 7,58 \\
Nível 2 G. V & 4 & 6,15 & 4 & 6,06 \\
Companhia Balcão & 1 & 1,54 & 1 & 1,52 \\
Novo Mercado & 42 & 64,62 & 41 & 62,12 \\
Sem Segmento & 9 & 13,85 & 10 & 15,15 \\
\hline Total & $\mathbf{6 5}$ & $\mathbf{1 0 0 , 0 0}$ & $\mathbf{6 6}$ & $\mathbf{1 0 0 , 0 0}$ \\
\hline
\end{tabular}

Fonte: Dados da pesquisa.

Entre os setores econômicos definidos pela BM\&FBovespa, não foi abordado o setor "Financeiro e Outros", que reúne subsetores como, por exemplo, intermediários financeiros, previdência e seguros, e serviços financeiros diversos. Destacam-se, no setor de utilidade pública, as empresas de energia elétrica. Nos anos de análise, o subsetor de "Energia Elétrica" possuí 12 empresas em 2014 e 11 empresas em 2015, com 18,5\% e 16,7\%, respectivamente.

Em seguida, temos o subsetor de "Alimentos Processados", com 12,3\% e 13,6\% das empresas cadastradas, dos seguintes segmentos: Açúcar e Álcool, Alimentos Diversos, Carnes e Derivados, e Laticínios, pertencentes ao setor "Consumo não Cíclico"; e o subsetor "Transporte", com 10,8\% e 13,6\%, nos anos de 2014 e 2015, respectivamente, do segmento Exploração de Rodovias, Serviços de Apoio e Armazenagem, Transporte Aéreo, Transporte Ferroviário, Transporte Hidroviário e Transporte Rodoviário, pertencentes ao setor de "Construção e Transporte".

Os setores de "Construção e Transportes e o "Consumo não Cíclico" apresentaram aumento nos períodos analisados, de $16,9 \%$ para $21,2 \%$ e de $18,5 \%$ para $21,2 \%$, respectivamente. Uma empresa pertencente à pesquisa não possuía cadastro em nenhum dos segmentos citados pela BM\&FBovespa. 
Os seguintes setores permaneceram com os mesmos números de empresas nos anos de 2014 e 2015: Bens Industriais, Materiais Básicos, Telecomunicações e Petróleo, Gás e Biocombustível. A diferença nos percentuais deve-se ao quantitativo de empresas que de um ano para outro, sendo 65 empresas pesquisadas em 2014 e em 2015 foram 66 empresas, conforme Tabela 2.

Tabela 2 - Setores. 2014-2015.

\begin{tabular}{|c|c|c|c|c|c|}
\hline \multirow{2}{*}{ SETOR } & \multirow{2}{*}{ SUBSETOR } & \multicolumn{2}{|l|}{2014} & \multicolumn{2}{|l|}{2015} \\
\hline & & $\mathbf{N}^{\circ}$ Empresas & $\%$ & $\mathbf{N}^{\circ}$ Empresas & $\%$ \\
\hline \multirow{6}{*}{ Bens Industriais } & Comércio & 0 & $0,0 \%$ & 0 & $0,0 \%$ \\
\hline & Equipamentos Elétricos & 0 & $0,0 \%$ & 0 & $0,0 \%$ \\
\hline & Máquinas e Equipamentos & 0 & $0,0 \%$ & 0 & $0,0 \%$ \\
\hline & Material de Transporte & 2 & $3,1 \%$ & 2 & $3,0 \%$ \\
\hline & Serviços & 0 & $0,0 \%$ & 0 & $0,0 \%$ \\
\hline & Total & 2 & $3,1 \%$ & 2 & $3,0 \%$ \\
\hline \multirow{3}{*}{ Construção e Transporte } & Construção e Engenharia & 4 & $6,2 \%$ & 5 & $7,6 \%$ \\
\hline & Transporte & 7 & $10,8 \%$ & 9 & $13,6 \%$ \\
\hline & Total & 11 & $16,9 \%$ & 14 & $21,2 \%$ \\
\hline \multirow{8}{*}{ Consumo Cíclico } & Comércio & 6 & $9,2 \%$ & 6 & $9,1 \%$ \\
\hline & Diversos & 3 & $4,6 \%$ & 1 & $1,5 \%$ \\
\hline & Hotéis e Restaurantes & 0 & $0,0 \%$ & 0 & $0,0 \%$ \\
\hline & Mídia & 0 & $0,0 \%$ & 0 & $0,0 \%$ \\
\hline & \begin{tabular}{|l|} 
Tecidos. Vestuário e Calçados \\
\end{tabular} & 0 & $0,0 \%$ & 0 & $0,0 \%$ \\
\hline & Utilidades Domésticas & 0 & $0,0 \%$ & 0 & $0,0 \%$ \\
\hline & Viagens e Lazer & 1 & $1,5 \%$ & 1 & $1,5 \%$ \\
\hline & Total & 10 & $15,4 \%$ & 8 & $12,1 \%$ \\
\hline \multirow{8}{*}{ Consumo não Cíclico } & Agropecuária & 0 & $0,0 \%$ & 0 & $0,0 \%$ \\
\hline & Alimentos Processados & 8 & $12,3 \%$ & 9 & $13,6 \%$ \\
\hline & Bebidas & 0 & $0,0 \%$ & 0 & $0,0 \%$ \\
\hline & Comércio e Distribuição & 0 & $0,0 \%$ & 1 & $1,5 \%$ \\
\hline & Diversos & 0 & $0,0 \%$ & 0 & $0,0 \%$ \\
\hline & Produtos de Uso Pessoal e de Limpeza & 0 & $0,0 \%$ & 0 & $0,0 \%$ \\
\hline & Saúde & 4 & $6,2 \%$ & 4 & $6,1 \%$ \\
\hline & Total & 12 & $18,5 \%$ & 14 & $21,2 \%$ \\
\hline \multirow{7}{*}{ Materiais Básicos } & Embalagens & 0 & $0,0 \%$ & 0 & $0,0 \%$ \\
\hline & Madeira e Papel & 2 & $3,1 \%$ & 2 & $3,0 \%$ \\
\hline & Materiais Diversos & 0 & $0,0 \%$ & 0 & $0,0 \%$ \\
\hline & Mineração & 3 & $4,6 \%$ & 2 & $3,0 \%$ \\
\hline & Químicos & 0 & $0,0 \%$ & 1 & $1,5 \%$ \\
\hline & Siderurgia e Metalurgia & 3 & $4,6 \%$ & 3 & $4,5 \%$ \\
\hline & Total & 8 & $12,3 \%$ & 8 & $12,1 \%$ \\
\hline \multirow{3}{*}{ Tecnologia da Informação } & Programas e Serviços & 2 & $3,1 \%$ & 2 & $3,0 \%$ \\
\hline & Computadores e equipamentos & 1 & $1,5 \%$ & 0 & $0,0 \%$ \\
\hline & Total & 3 & $4,6 \%$ & 2 & $3,0 \%$ \\
\hline \multirow{3}{*}{ Telecomunicações } & Telefonia Fixa & 1 & $1,5 \%$ & 1 & $1,5 \%$ \\
\hline & \begin{tabular}{|l|} 
Telefonia Móvel \\
\end{tabular} & 1 & $1,5 \%$ & 1 & $1,5 \%$ \\
\hline & Total & 2 & $3,1 \%$ & 2 & $3,0 \%$ \\
\hline \multirow{4}{*}{ Utilidade Pública } & Água e Saneamento & 1 & $1,5 \%$ & 1 & $1,5 \%$ \\
\hline & Energia Elétrica & 12 & $18,5 \%$ & 11 & $16,7 \%$ \\
\hline & Gás & 1 & $1,5 \%$ & 1 & $1,5 \%$ \\
\hline & Total & 14 & $21,5 \%$ & 13 & $19,7 \%$ \\
\hline \multirow{2}{*}{ Petróleo, gas e biocombustíveis. } & Petróleo, gas e biocombustíveis. & 2 & $3,1 \%$ & 2 & $3,0 \%$ \\
\hline & Total & 2 & $3,1 \%$ & 2 & $3,0 \%$ \\
\hline \multirow{2}{*}{ Não Classificada } & Não Classificada & 1 & $1,5 \%$ & 1 & $1,5 \%$ \\
\hline & Total & 1 & $1,5 \%$ & 1 & $1,5 \%$ \\
\hline \multicolumn{2}{|l|}{ Total } & 65 & $100,0 \%$ & 66 & $100,0 \%$ \\
\hline
\end{tabular}

Fonte: Dados da pesquisa. 


\subsection{Independência}

Com relação à independência, nota-se que em 2014, 9 empresas não atenderam a este requisito, o que representa $13,8 \%$, enquanto que em 2015,8 empresas não possuíam membros independentes, com 12,1\% da amostra. Entre os anos de 2014 e 2015, 86,2\% e 87,9\%, respectivamente, dos membros que compunham o comitê de auditoria eram independentes, atendendo as exigências dos órgãos reguladores. Em 2014, 23 empresas constavam com 2 membros independentes, sendo considerado 35,38\%, enquanto que em 2015, 22 empresas possuíam até 1 membro independente, ou seja, 33,33\% da amostra, de acordo com a Tabela 3.

Tabela 3 - Membros Independentes

\begin{tabular}{|c|c|c|c|c|}
\hline \multirow{2}{*}{$\begin{array}{l}\text { Membros } \\
\text { Independentes }\end{array}$} & \multicolumn{2}{|c|}{2014} & \multicolumn{2}{|c|}{2015} \\
\hline & $\begin{array}{c}\text { Quant. } \\
\text { Empresas }\end{array}$ & $\%$ & $\begin{array}{c}\text { Quant. } \\
\text { Empresas }\end{array}$ & $\%$ \\
\hline Nenhum & 9 & 13,8 & 8 & 12,1 \\
\hline 1 membro & 19 & 29,2 & 22 & 33,3 \\
\hline 2 membros & 23 & 35,4 & 21 & 31,8 \\
\hline 3 membros & 11 & 16,9 & 9 & 13,6 \\
\hline 4 membros & 3 & 4,6 & 5 & 7,6 \\
\hline 5 membros & 0 & 0,0 & 1 & 1,5 \\
\hline Total & 65 & 100 & 66 & 100 \\
\hline
\end{tabular}

Fonte: Dados da pesquisa.

No ano de 2015, 5 empresas possuíam 4 membros independentes (7,58\% da amostra), maior que do ano de 2014, onde eram 3 empresas, representando 4,62\%. Verificou-se que em 2015, uma empresa tinha o comitê de auditoria, composto por 5 membros independentes. Este quantitativo não foi observado em 2014.O estudo de Cunha et al. (2013) observou que os membros independentes se concentram na faixa de 3 membros, com 44,85\%, depois 02 membros, com 20,96\%, atendendo as determinações da CVM (2002) e IBGC (2009) em manter a maioria dos seus membros independentes para que não haja influência na capacidade de ser imparcial na análise das demonstrações contábeis e financeiras e pareceres sobre a gestão da organização.

\subsection{Expertise}

Verificou-se que em 2014 a maioria dos membros do comitê de auditoria possuíam a formação em Engenharia, Economia, Administração e Contabilidade, com 22\%, 21\%, 16,7\% e 15,3\%, respectivamente. Enquanto que em 2015, a qualificação mais comum dos membros era em Economia, Administração, Engenharia e Contabilidade, com 21,3\%, 18,5\%, 17,5\% e 13,7\%, respectivamente. Guzzo (2014) identificou que quanto à formação profissional dos integrantes, as mais comuns são Engenharia, Economia, Finanças e Contabilidade.

Em 2014, a quantidade de membros do comitê de auditoria era de 209 membros e em 2015 foi de 211. Destes, 22,5\% possuíam expertise desejada no ano de 2014 e em 2015 este número reduziu para 19,4\%. Os membros considerados com expertise foram retirados das informações do Formulário de Referência, subseção 12.7, no site da BM\&FBovespa.A formação que mais aparece de expertise é a de contador em ambos os anos da pesquisa, logo em seguida em 2014, bancário aparece com 2,4\%, enquanto que em 2015, economista aprece em segundo lugar, com 2,4\%.

Cunha et al. (2013) observou em seu estudo que em 2013, havia apenas um membro com a qualificação em auditoria. Nota-se que em 2014 havia um membro qualificado nesta área e em 2015 passou para 2 membros auditores. Os membros com formação em Contabilidade apareceram nos seus estudos com as seguintes quantidades: 24 membros (14,05\%), em 2012 e 26 membros (13,54\%) em 2013. Do total de 185 e 192 membros, respectivamente. Observa-se que em 2014, 32 
(15,3\%) membros, do total de 209, possuíam formação em Ciências Contábeis e em 2015, 29 membros $(13,7 \%)$ dos 211 tinham esta qualificação, conforme Tabela 4.

Tabela 4 - Qualificação dos membros

\begin{tabular}{l|c|c|c|c}
\hline \multirow{2}{*}{ Qualificação } & \multicolumn{2}{|c|}{$\mathbf{2 0 1 4}$} & \multicolumn{2}{|c}{$\mathbf{2 0 1 5}$} \\
\cline { 2 - 5 } & Quant. & $\mathbf{\%}$ & Quant. & $\mathbf{\%}$ \\
\hline Administrador & 35 & $16,7 \%$ & 39 & $18,5 \%$ \\
Advogado & 17 & $8,1 \%$ & 23 & $10,9 \%$ \\
Arquiteto & 1 & $0,5 \%$ & 1 & $0,5 \%$ \\
Auditor & 1 & $0,5 \%$ & 2 & $0,9 \%$ \\
Bancário & 5 & $2,4 \%$ & 1 & $0,5 \%$ \\
Cirurgião Dentista & 1 & $0,5 \%$ & 1 & $0,5 \%$ \\
Consultor & 1 & $0,5 \%$ & 0 & $0,0 \%$ \\
Contador & 32 & $15,3 \%$ & 29 & $13,7 \%$ \\
Controller & 1 & $0,5 \%$ & 1 & $0,5 \%$ \\
Diplomata Aposentado & 1 & $0,5 \%$ & 1 & $0,5 \%$ \\
Economista & 44 & $21,1 \%$ & 45 & $21,3 \%$ \\
Empresário & 7 & $3,3 \%$ & 8 & $3,8 \%$ \\
Engenheiro & 46 & $22,0 \%$ & 37 & $17,5 \%$ \\
Especialista Financeiro & 3 & $1,4 \%$ & 3 & $1,4 \%$ \\
Estatístico & 0 & $0,0 \%$ & 1 & $0,5 \%$ \\
Executivo & 1 & $0,5 \%$ & 2 & $0,9 \%$ \\
Filósofo & 0 & $0,0 \%$ & 1 & $0,5 \%$ \\
Físico & 3 & $1,4 \%$ & 2 & $0,9 \%$ \\
Jornalista & 1 & $0,5 \%$ & 1 & $0,5 \%$ \\
Médico & 2 & $1,0 \%$ & 2 & $0,9 \%$ \\
Portfolio Manager & 1 & $0,5 \%$ & 1 & $0,5 \%$ \\
Professor & 2 & $1,0 \%$ & 2 & $0,9 \%$ \\
Psicólogo & 0 & $0,5 \%$ & 1 & $0,5 \%$ \\
Relações Internacionais & 3 & $1,4 \%$ & 4 & $1,9 \%$ \\
Sem dados & 0 & $0,0 \%$ & 1 & $0,5 \%$ \\
Técnico Administração & 0 & $0,0 \%$ & 1 & $0,5 \%$ \\
Tecnólogo Processamento & $\mathbf{2 0 0} \%$ & $\mathbf{2 1 1}$ & $\mathbf{1 0 0} \%$ \\
Dados & & &
\end{tabular}

Fonte: Dados da pesquisa.

\subsection{Tamanho}

Em relação ao tamanho, em 2014, das 65 empresas pesquisadas, 50,8\% possuíam 3 membros e em 2015, este número foi de 30 empresas, do total de 66 pesquisadas, representando 45,5\%. Com isso, nota-se, que a maioria das empresas atenderam aos órgãos reguladores, de possuir no mínimo 3 membros nos comitês, em 2014, 75,4\% e em 2015, 74,2\% dessas empresas cumpriram com este requisito, de acordo com a tabela 4.

Em 2014, uma empresa da amostra tinha um comitê com até 8 membros, este número não se repetiu em 2015, entretanto, 2 empresas constavam com até 7 membros neste ano, representando 3\% da amostra. Houve uma redução no percentual de 3 membros nos anos analisados, contudo, houve uma elevação no número de 4 membros e 5 cinco membros.

Os resultados do estudo de Cunha et al. (2013) mostraram que em relação ao tamanho, grande parte das empresas possuíam três membros participantes do comitê de auditoria, com 69,11\% em 2012 e 69,12\% em 2013. Das empresas pesquisadas, em 2014, nota-se que 24,6\% e em 2015, 25,8\% não atenderiam a determinação da Blue Ribbon Committee (1999), CVM, em sua instru- 
ção $n^{\circ}$ 509, da Lei Sarbanes-Oxley, da Resolução 3.198/04, no seu Art. 12 e a Resolução № 3170/04, em seu Art. 11 do BACEN. Por possuírem comitê de auditoria com um número inferior de membros preconizados por estes órgãos.

Tabela 5 - Quantidade de Membros

\begin{tabular}{l|c|c|c|c}
\hline \multirow{2}{*}{$\begin{array}{l}\text { Quantidade } \\
\text { de membros }\end{array}$} & \multicolumn{4}{|c}{ Quantidade de empresas } \\
\cline { 2 - 5 } 1 membro & $\mathbf{2 0 1 4}$ & $\mathbf{\%}$ & $\mathbf{2 0 1 5}$ & $\mathbf{\%}$ \\
2 membros & 12 & 6.15 & 2 & 3.03 \\
3 membros & 33 & 50.77 & 30 & 45.45 \\
4 membros & 9 & 13.85 & 11 & 16.67 \\
5 membros & 3 & 4.62 & 5 & 7.58 \\
6 membros & 3 & 4.62 & 1 & 1.52 \\
7 membros & 0 & 0.00 & 2 & 3.03 \\
8 membros & 1 & 1.54 & 0 & 0.00 \\
\hline Total & 65 & 100 & 66 & 100 \\
\hline Fonte: Dados da pesquisa.
\end{tabular}

\subsection{Estatísticas Descritivas das Características dos Comitês de Auditoria}

Nesta parte do estudo, observa-se aplicação da estatística descritiva (mínimo, máximo, média, moda, mediana e desvio padrão) na variável independência, expertise e tamanho dos comitês de auditoria das empresas analisadas nos anos de 2014, com o total de 65 empresas e 66 empresas em 2015, onde os resultados estão resumidos na Tabela 6.

Tabela 6 - Tamanho do comitê de auditoria

\begin{tabular}{l|cccccc}
\hline \multicolumn{7}{c}{$\mathbf{2 0 1 4}$} \\
\hline Característica & Mínimo & Máximo & Média & Moda & Mediana & Desvio Padrão \\
\hline Independência & 0 & 3 & 1.69 & 2.00 & 2.00 & 1.06 \\
Expertise & 1 & 6 & 3.11 & 3.00 & 3.00 & 1.05 \\
Tamanho & 1 & 8 & 3.22 & 3.00 & 3.00 & 1.19 \\
\hline \multicolumn{7}{|c}{} \\
\hline Característica & Mínimo & Máximo & Média & Moda & Mediana & Desvio Padrão \\
\hline Independência & 0 & 5 & 1.76 & 1.00 & 2.00 & 1.16 \\
Expertise & 0 & 4 & 0.62 & 0.00 & 0.00 & 0.84 \\
Tamanho & 1 & 7 & 3.20 & 3.00 & 3.00 & 1.19 \\
\hline
\end{tabular}

Fonte: Dados da Pesquisa.

Assim como foi observado no estudo de Cunha et al. (2013), o tamanho máximo do comitê de auditoria estava entre 1 a 8 membros entre os anos de 2012 e 2013, verificou-se em 2014 que a amostra observada obteve os mesmos resultados, enquanto que em 2015 o tamanho do comitê de auditoria estava entre 1 e 7 membros. A moda e a mediana de 3 membros e a média de 3,22 em 2014 e 3,20, em 2015, atende em sua maioria às recomendações da CVM, em sua instrução $n^{\circ} 509$, à Lei Sarbanes-Oxley, à Resolução № 3.198/04, no seu art. 12 e a Resolução № 3.170/04, em seu art. 11 do BACEN, deter no mínimo 3 membros.

Guzzo (2014) e Chiachio et al. (2015) também constataram que, em média, o tamanho do comitê é de 3 integrantes, o que nos permite verificar, que as empresas estão seguindo as recomendações das legislações, entretanto, ao analisar o desvio padrão nos períodos, observa-se que a amostra é heterogênea, ou seja, existe uma elevada dispersão e baixa concentração de dados em torno da média, deste modo, grande quantidade dos valores se distinguem da média. Observada a vulnerabilidade da média, atesta-se que o comitê é composto de 03 membros através da análise da 
mediana e da moda, em todos os anos pesquisados. Com isso, em relação à característica tamanho, há uma conformidade e aderência à legislação e recomendações vigentes.

Quanto à expertise, em 2014, de acordo com a Tabela 1, o número de membros no comitê de auditoria com esta característica varia de 1 a 6 integrantes. A moda e mediana de 3 e a média de 3,11 expressam que a maioria das empresas possui no mínimo 3 membros com expertise, atendendo as exigências do IBCG que recomenda o mínimo de 1 membro. Para a expertise, foi considerada a formação e experiência profissional dos membros do comitê de auditoria indicadas no Formulário de Referência, subseção 12.7. Em 2015, nota-se empresas com membros sem expertise em contabilidade, finanças ou auditoria, indicando a não conformidade com as práticas indicadas pelo IBGC (2009), a Lei Sarbanes-Oxley e o BACEN. No entanto, os métodos estatísticos demonstraram uma amostra heterogênea, através do desvio padrão, sendo a amostra considerada heterogênea neste quesito. A partir da moda, observa-se que 1 membro foi o valor mais encontrado nos anos pesquisados.

Quanto à independência dos membros, em 2014 a amostra apresentou uma média de 1,69 e a moda 2, com a quantidade de membros entre 0 a 3 membros, enquanto que em 2015 a média foi de 1,76 e a moda 1, e a quantidade de membros entre 0 a 5 membros. A independência é indicada por órgãos como IBGC, que orienta que seja constituído, de preferência, por conselheiros independentes ou, pelo menos, que sua maioria seja independente, a CVM e a lei Sarbanes-Oxley (2002) na seção 301. Tendo a moda com 2 membros em 2014 e 1 em 2015. O estudo de Cunha et al. (2013) observou que há organizações com até 07 membros independentes em seus comitês de auditoria em 2012 e até 08 membros em 2013, porém, sua percepção não é homogênea visto que o coeficiente de variação se demonstrou maior que 30\% e o desvio padrão praticamente não se alterou no decorrer dos anos pesquisados, atrelando a essas amostras uma alta dispersão dos dados e um distanciamento de informações próximas a média encontrada.

Mesmo com recomendações de órgãos nacionais e a lei internacional, verifica-se que algumas empresas ainda não atendem por completo essas orientações em relação às características pesquisadas, como o tamanho, a expertise e a independência. Essa observação foi verificada com Cunha et al. (2013), que concluiu que há empresas que não atendem os preceitos mínimos das práticas recomendadas no que concerne ao tamanho, independência e expertise. Porém, a maior parte das organizações contempladas nesse estudo atende as especificações recomendadas em relação às características: tamanho, independência e expertise, que são predominantes em todas empresas que possuem o comitê de auditoria formalizado.

\section{CONSIDERAÇÕES FINAIS}

O objetivo deste estudo foi verificar as características do comitê de auditoria de 65 empresas nos anos de 2014 e em 2015 com 66 empresas comparativamente aos anos de 2012 e 2013, utilizando-se das informações publicadas nos formulários de referência. Foram excluídas as instituições financeiras e seguradoras, pois são vinculadas aos órgãos reguladores BACEN e SUSEP, respectivamente, sendo analisadas apenas as empresas que possuíam comitês de auditoria constituídos.Em relação à governança corporativa, grande parte das empresas pertence ao Novo Mercado, com $64,62 \%$ (2014) e 62,12\% (2015) das empresas, e com crescimento nos setores de Construção e Transportes, com 16,9\% e 21,2\%. Consumo Não Cíclico, com 18,5\% e 21,2\% e o setor de Utilidade Pública, que, mesmo com uma redução em 2015, ainda é o setor representativo, com 21,5\% e 19,7\%, estando o subsetor Energia Elétrica, com 18,5\% e 16,7\%, nas de 2014 e 2015, respectivamente.

Sobre a característica independência, os resultados obtidos mostram que em $2014,35 \%$ das empresas pesquisadas, ou seja, 23 empresas, possuíam 2 membros independentes, e 86,1\% das empresas atendiam a estas características, com 1 ou mais membros independentes, sendo representado por 56 empresas e com 9 empresas sem nenhum membro independente, com 13,8\%. Em 2015, 
8 empresas não constavam com membros independentes, tendo o resultado de $12,1 \%$, e a maior concentração entre 1 e 2 membros, representando 65,1\% da amostra, e o total de 43 empresas. Com esses resultados, a independência atendeu as boas práticas de governança corporativa.

Quanto à expertise, em 2014, o comitê de auditoria constava com 209 membros, destes, as profissões que prevaleceram foram das seguintes áreas: Engenharia, Economia, Administração e Contabilidade, com $22 \%, 21,1 \%, 16,7 \%$ e $15,6 \%$, respectivamente. Neste período $22,5 \%$ dos membros atendiam a recomendações quanto à expertise, fato confirmado através da estatística descritiva, com no mínimo 1, no máximo 6 membros, e média de 3,11 membros com esta característica. Já que em 2015, de um total de 211 membros, as áreas de formação eram em Economia (21,3\%), Administração (48,5\%), Engenharia (17,5\%) e Contabilidade (23,7\%), totalizando $19,4 \%$ de membros com a formação desejada, havendo algumas empresas sem nenhum membro com expertise desejada até o máximo de 4 membros, com a média de $0,62 \%$ no período, o que demonstra que ainda há empresas que não atendem às recomendações do IBGC, CMV, BACEN e a Lei Sarbanes-Oxley.

A característica tamanho foi atendida nos períodos analisados, com 50,8\% das empresas listadas composta por 3 membros (33 empresas), e em 2015, com 45,5\% (30 empresas) com 3 membros. Porém, 16 empresas, o que equivale a 24,7\% e 17 empresas (25,7\%), nos anos de 2014 e 2015, respectivamente, não atendiam a estas recomendações. A quantidade de membros no comitê é uma característica heterogênea, sendo que este quantitativo varia de 1 a 8 componentes no comitê, com 49 empresas, correspondendo a 75,3\% e 74,3\%, respectivamente, das empresas estavam com 3 ou mais membros.

O presente estudo pôde reforçar o que pesquisas anteriores verificaram, que mesmo com órgão recomendado a formação dos comitês de auditoria, ainda existem empresas que não atendem a todas essas orientações. Este tema é bem amplo e abre espaço para muitas linhas de pesquisa. Pesquisas futuras poderiam analisar o porquê dessas empresas estruturaram comitê de auditoria, mas qual o motivo que as fazem não atender completamente a estes órgãos? Um outro estudo é verificar se as instituições financeiras atendem as recomendações do BACEN. Mesmo com várias recomendações de participação de especialistas nos comitês, porque algumas empresas não possuem nenhum especialista? Essas empresas que possuem comitês de auditoria conhecem as recomendações dos órgãos reguladores?

Pode-se verificar que algumas recomendações existentes sobre constituição dos comitês de auditoria surgiram neste século XXI e que apesar dos vários estudos sobre este tema, existem empresas que possuem comitê de auditoria, mas que ainda não atendem por completo as recomendações.

\section{REFERÊNCIAS}

Almeida, C. A. L. (2008). A atuação dos comitês de auditorias e conselhos fiscais nas empresas brasileiras sujeitas à regulamentação da SEC -Securities and Exchange Commission dos Estados Unidos da América. Dissertação de Mestrado, Pontifícia Universidade Católica de São Paulo, São Paulo, SP, Brasil.

Antunes, J.,Honorato, W. R., \& Antunes, G. M. B. (2016). Importância da atuação dos comitês de auditoria nos trabalhos dos auditores independentes de companhias abertas brasileiras. Recuperado em 5 de maio, 2016, de http://docplayer.com.br/3813907-Palavras-chave-auditoria-interna-controle-internolei-sarbanes-oxley.html.

Baioco, V. G. (2015). Efeitos do Comitê de Auditoria e do Conselho Fiscal na qualidade da informação contábil no Brasil, 2015. Dissertação de Mestrado, Universidade Federal do Espírito Santo, Vitória, SC, Brasil. 
Blue Ribbon Committee. (1999). Reporting and recommendations of the Blue Ribbon Committee on improving the effectiveness of corporate audit committee. New York: New York Exchange and National Association of Securities Dealers. New York.

Chatterjee, D. (2011). Audit committee observation/recommendations versus practices as a compliance of corporate governance in India.DSLU Business \& Economics Review, 20(2), 67-78.

Chiachio, V. F. O.,Silva, S. F.,Reina, D.,Reina, D. R. M.,\& Hehr, D. A. (2016). Comitê de Auditoria: O Nível de Aderência das Companhias Listadas na BM\&FBovespa às Melhores Práticas de Governança Corporativa. Cong. USP de Iniciação Científica em Contabilidade. Recuperado em 5 de maio, 2016, de http://www.congressousp.fipecafi.org/web/artigos152015/104.pdf.

Chiodini, D. M.,Souza, M. M.,Borba, J. A.,Ducati, E. (2013). Adequação das companhias que atuam no Brasil à governança corporativa: O comitê de auditoria. $R$. Cont. UFBA, 7(1), 21-35.

Comissão de Valores Mobiliários. (2011). Instrução CVM n509, de 16 de novembro de 2011. Acrescenta artigos à Instrução CVM nº 308, de 14 de maio de 1999, e altera artigos e Anexos da Instrução CVM no 480, de 7 de dezembro de 2009, Rio de Janeiro.

Conselho Nacional de Seguros Privados. (2004). Resolução CNSP N 118. Recuperado em 5 de maio, 2016, de http://www.susep.gov.br/textos/resol118-04.pdf.

Cunha, P. R.,Sant'ana, S. V.,Theis, M. B.,Krespi, N. T. (2013). Características do comitê de auditoria e os reflexos no gerenciamento de resultados nas empresas listadas na BM\&FBOVESPA. Revista de Contabilidade do Mestrado em Ciências Contábeis da UERJ (online), 18(3), 2-19.

Cunha, P. R.,Hillesheim, T.,Faveri, D. B., \& Rodrigues Junior, M. M. (2014). Características do comitê de auditoria e o gerenciamento de resultados: um estudo nas empresas listadas na BM\&FBOVESPA. Revista de Contabilidade e Organizações, 22, 15-25.

Cunha, P. R., Hillesheim, T., Faveri, D. B., \& Rodrigues Junior, M. M. (2015). Relação entre as Características do Comitê de Auditoria e o Atraso da Emissão do Relatório da Auditoria Independente (AuditDelay). Contabilidade, Gestão e Governança, 18(3), 47-65.

Cunha, P. R.,Pletsch, C. S.,\& Silva, A. (2015). Relação entre as Características da Empresa, do Comitê de Auditoria e do Auditor Independente com o Prazo de Publicação das demonstrações Financeiras. Revista de Educação e Pesquisa em Contabilidade, 9(4), 415-429.

De Luca, M. M. M., Martins, L. C., Maia, A. B. G. R., \& Coelho, A. C. D. (2010). Os mecanismos de Auditoria evidenciados pelas empresas listadas nos níveis diferenciados de Governança Corporativa e no Novo Mercado da Bovespa. Contabilidade Vista \& Revista, 21(1), 101-130.

Erkens, D. H., \& Bonner, S. E. (2012). The role of firm status in appointments of accounting financial experts to audit committees. The Accounting Review, 88(1), 107-136.

Furuta, F. (2010). A relação das características das empresas com a adoção do comitê de auditoria $x$ conselho fiscal adaptado. Doutorado em Ciências Contábeis, Universidade de São Paulo, São Paulo, SP, Brasil. 
Furuta, F., \& dos Santos, A. (2010). Comitê de auditoria versus conselho fiscal adaptado: a visão dos analistas de mercado e dos executivos das empresas que possuem ADRs. Revista Contabilidade E Finanças, 21(53), 1-23.

Gil, A. C. (2007). Como elaborar projetos de pesquisa. 4. ed. São Paulo: Atlas.

Guariente, L. A. (2008). Atributos e papéis dos comitês de auditoria na implantação das boas práticas de governança corporativa em instituições financeiras. Dissertação de Mestrado, Pontifícia Universidade Católica de Minas Gerais, Belo Horizonte, MG, Brasil.

Guzzo, E. J. (2014). Disclosure da composição do comitê de auditoria: análise sob a ótica das características, diversidade e interligações. Dissertação de Mestrado, Universidade Federal de Santa Catarina, Florianópolis, SC, Brasil.

Instituto Brasileiro de Governança Corporativa. (2009). Código das melhores práticas de governança corporativa. 5. ed. Instituto Brasileiro de Governança Corporativa. São Paulo: IBGC.

Iudícibus, S., \& Lopes, A. B. (2004). Teoria avançada da contabilidade. São Paulo: Atlas.

Klein, A. (2002). Audit committee, board of director characteristics, and earnings management. Journal of Accounting and Economics, 33(3), 375-400.

Marconi, M. A.,Lakatos, E. M. (2011). Técnicas de pesquisa: planejamento e execução de pesquisas, amostragens e técnicas de pesquisa, elaboração e interpretação de dados. 6. ed. São Paulo: Atlas.

Oliveira, M. C., \&Linhares, J. S. (2007). A implantação de controle interno adequado às exigências da Lei SARBANES-OXLEY em empresas brasileiras: Um estudo de caso. BASE: Revista de Administração e Contabilidade da Unisinos, 4(2), 160-170.

Peleias, I. R.,Segreti, J. B., \&Costa, C. A. (2009). Comitê de auditoria ou órgãos equivalentes no contexto da Lei Sarbanes-Oxley: estudo da percepção dos gestores de empresas brasileiras emitentes de American Depositary Receipts - ADRs. Revista Contabilidade Vista E Revista, 20(1), 41-65.

Sampieri, R. H.,Collado, C. F., \& Lucio, P. B. (2006). Metodologia de pesquisa. 3.ed. São Paulo: McGraw-Hill.

Santos, A. G. (2009). Comitê de auditoria: uma análise baseada na divulgação das informações de empresas brasileiras - São Paulo. Dissertação de Mestrado, Universidade de São Paulo, São Paulo, SP, Brasil.

Schmeider, C. F.,Cunha, P. R., \& Santos, V. (2015). Características do comitê de auditoria: um estudo nas empresas listadas na BM\&FBOVESPA. Anais do Seminários em Administração, São Paulo, SP, Brasil, 18.

Silva, L. M. (2007). A Influência da Lei Sarbanes-Oxley e do Código Civil Brasileiro nos Controles Internos de Empresas Localizadas no Brasil. Dissertação de Mestrado, Universidade do Vale do Rio dos Sinos, São Leopoldo, RS, Brasil. 
Silva, L. M., \& Machado, S. B. Z. (2008). Um estudo sobre os impactos da lei Sarbanes-Oxley na área de auditoria interna de uma empresa brasileira com ações negociadas nos Estados Unidos. Anais doCongresso Brasileiro de Contabilidade, Gramado, RS, Brasil, 18.

Silva, K. L., Oliveira, M. C., De, M. M. M., \& Araújo, O. C. (2009). A Implementação dos Controles Internos e do Comitê de Auditoria Segundo a Lei SOX: o Caso Petrobras. Contabilidade Vista E Revista, 20(3), 39-63.

Silveira, A. D. M. (2010). Governança corporativa no Brasil e no mundo: teoria e prática. Elsevier: Rio de Janeiro. 